\title{
Article
}

\section{Contemporary and Historical Evidence to Suggest that Women's Preference for Age at Birth of First Child Remains Consistent Across Time}

Hendrie, Colin A., Brewer, Gayle, Lewis, Hannah and Mills, Francesca

Available at http://clok.uclan.ac.uk/13568/

Hendrie, Colin A., Brewer, Gayle ORCID: 0000-0003-0690-4548, Lewis, Hannah and Mills, Francesca (2014) Contemporary and Historical Evidence to Suggest that Women's Preference for Age at Birth of First Child Remains Consistent Across Time. Archives of Sexual Behavior, 43 (7). pp. 1373-1378. ISSN 00040002

It is advisable to refer to the publisher's version if you intend to cite from the work. http://dx.doi.org/10.1007/s10508-014-0290-6

For more information about UCLan's research in this area go to http://www.uclan.ac.uk/researchgroups/ and search for < name of research Group>.

For information about Research generally at UCLan please go to http://www.uclan.ac.uk/research/

All outputs in CLoK are protected by Intellectual Property Rights law, including Copyright law. Copyright, IPR and Moral Rights for the works on this site are retained by the individual authors and/or other copyright owners. Terms and conditions for use of this material are defined in the policies page. 


\section{Contemporary and Historical Evidence to Suggest that Women's Preference for Age at Birth of First Child Remains Consistent across Time}

Colin A. Hendrie, Gayle Brewer, Hannah Lewis, and Francesca Mills

Women's ability to reproduce is restricted by menarche and menopause. First children are, however, not typically born until some years after the onset of puberty. Other factors therefore contribute towards this delay. In this context, women's hips do not reach full adult form until they are in their mid-20s. Therefore, physiological and morphological factors appear to determine an optimum age-range for reproduction. The following studies were conducted in order to investigate this hypothesis. Study 1 asked nulliparous women questions about ages at which particular life events related to reproduction should ideally occur. This revealed their preferred age at birth of first child to be approximately 27 years old. Study 2 replicated these findings and further showed that women with children actually had their first child at a very similar age $[27.93( \pm 0.79)]$. Findings from Study 3 were also remarkably consistent $[28.15( \pm 0.39)]$. Study 4 examined the 1901 UK Census record and incorporated an analysis of the influence of wealth. Middle class women were on average $24.88( \pm 0.22)$ years old at the birth of their first child. Poor women were on average $23.50( \pm 0.20)$ years old. These figures at least approximate to findings from Studies 1-3, which is noteworthy given that modern contraceptive methods were not widely available at the time. It is concluded that female strategies to delay giving birth to their first child until they are of an age that approaches or coincides with their full hip maturation are enduring across time.

Keywords: birth; children; lifeplan; obstetric dilemma; women 


\section{INTRODUCTION}

Humans are a species characterized by a relatively low number of offspring and high parental investment (Martin, 2007). Given this low reproductive rate, timing is of particular importance, especially so for the birth of the first child. The fertility of females of our species is limited by menarche and menopause. There are also severe consequences for the quality of offspring associated with poor timing of reproduction, such as very early or late childbearing (Schwarz, Smith, Steinauer, Reeves, \& Cauhey, 2008).

Other factors women must take into account are quality of available partners, resource availability, likelihood of disease, and their own physical limitations (Benzies et al., 2006). The relatively slow rate of hip growth whereby full adult form is not reached until the mid20s (e.g., Sheiner, Levy, Katz, \& Mazor, 2005) represents a further restriction. Additional considerations are that men can be required to make significant paternal investment (Geary, 2000; Gettler, 2010) and that women's ability to raise high quality offspring are affected if that investment is not made (Beise, 2005). Hence, there is a courtship process by which men's commitment and willingness to share resources are tested (Buss \& Schmitt, 1993; Kenrick, Sadalla, Groth, \& Troth, 1990). This courtship period also helps women to become immune to a male's potentially teratogenic infections (Hendrie \& Brewer, 2010). Therefore, assuming pregnancy is not the result of forced copulation, coercion or some other involuntary factor, there is a clear process that precedes and leads up to women's decisions to reproduce.

With regard to physical limitations, teenage pregnancy is associated with a number of medical complications (Creatsas \& Elsheikh, 2002; Jolly, Sebire, Harris, Robinson, \& Regan, 2000), including an increased risk of neonatal and postnatal mortality (Chen, Wen, Fleming, Yang, \& Wang, 2008; Phipps, Blume, \& DeMonner, 2002). Further, teenage mothers are more likely to experience pre-term delivery (Chahande, Jadho, Wadhya, \& Udhade, 2002), which is thought to be a consequence of immature pelvic architecture (Guegan, Teriokhin, \& 
Thomas, 2000). As a result, the babies of teenage mothers tend to weigh less (Cunnington, 2001). This increases their vulnerability to developmental problems and ill health even through to adulthood (Lawlor, Smith, \& Ebrahim, 2004; Richards, Hardy, Kuh, \& Wadsworth, 2001).

Risks associated with reproduction at an older age include declining fertility and chromosomal abnormalities (Asada et al., 2000; Bosch, Rajmil, Martinez-Pasarell, Egozcue, \& Templado, 2001; Volarcik et al., 1998). It is estimated that as many as half of all the remaining eggs of women aged over 50 are chromosomally compromised (Hassold, 1986). Older mothers (i.e., over the age of 35) face increased risks of diabetes, chronic hypertension, haemorrhage, cardiomyopathy (Callaghan \& Berg, 2003; Salihu, Shumpert, Slay, Kirby, \& Alexander, 2003), and a greater risk of dying from pregnancy related causes (Callaghan \& Berg, 2003). There are also increased risks of fetal mortality and premature birth (Salihu et al., 2003). These adverse effects for both younger and older women are more pronounced in those geographical locations and historical times where access to medical care is or was not freely available (McClure, Goldenberg, \& Bann, 2007).

There are hence limitations on when reproduction can begin and must end. These factors are further complicated by the obstetric dilemma created by the conflicting demands of childbirth and bipedal locomotion (Rosenberg \& Trevathan, 2002) and the relatively slow rate of hip growth such that full adult form is not reached until women are in their mid-20s (Sheiner et al., 2005). Therefore, physiological and morphological factors appear to determine an optimum age-range for reproduction. The following studies were conducted in order to investigate this hypothesis. This was examined in nulliparous women and those with at least one child. The historical record was also consulted. 


\section{METHOD}

\section{Participants}

\section{Studies 1-3}

Fifty female participants aged between 17 and 27 years $(M=24.46+3.87)$ took part in Study 1. Study 2 involved two groups, 53 women who had not yet had children were aged between 18 and $29(\mathrm{M}=21.78+.28)$ and 52 women aged between 35 and $62(\mathrm{M}=49.23+$ 1.07) who had at least one child. Study 3 involved 147 women aged between 37 and $64(\mathrm{M}=$ $52.17+.46)$ who also had at least one child. Participants in each of these studies were opportunity sampled from around the University of Leeds and its environs. No other recruitment measures were employed and no compensation was offered for taking part in the study.

Women in Studies 1 and 2 were asked a range of biographical questions to do with age, career/education history, and relationship status. In Study 1, they were also asked to state the age at which they thought certain key life events (such as falling in love, getting married, having children) should ideally occur. Study 2 also involved questions about ideal ages for particular life events and additionally asked women to give their ages at the time when these events actually occurred in their lives. For both these studies, questions were phrased as "In the spaces provided below, please suggest the age that you believe in your opinion to be the 'ideal' age when encountering ..." followed by the particular life even. In Study 2, there was an addition of a second part to the question "and (if already experienced) when did this occur?" Women in Study 3 were only asked to give their ages, ages at the birth of their first child, and total number of children.

\section{Study 4}

Census records of 873 women aged 47 or less with children of the same surname living with them were obtained from the 1901 UK census archives. These records were 
selected on the basis of women having lived on either "poor" or "middle class" streets as classified by the Charles Booth Archive of the Poverty Maps of London (Booth, 1902). "Poor" in Booth's terminology were those with intermittent earnings rather than suffering from chronic want, while the middle class were "well to do" rather than wealthy. This map was compiled between the years 1898 and 1899 and is hence almost exactly contemporaneous with the census information. There were 474 "poor" women with a mean age of $34.7( \pm .33)$ years and 399 "middle class" women $(M=35.16 \pm .36$ years $)$. Each woman's age at the birth of her first child was calculated by subtracting the eldest child's age from her age at the time of the census. Data from a small number of women $(N=10,5$ of each class) whose ages at the birth of their first child were indicated as being 14 or below (the mean age of menarche at this time [Brown, 1966; LaVelle, 1994]) were discounted as error (most likely produced as the result of husbands with children from previous marriages having remarried younger wives). The upper age limit for the sample was set at 47 because this was the estimated mean age of menopause in 1900 (Backman, 1948).

\section{RESULTS}

\section{Study 1}

A one-way within-subjects analysis of variance (ANOVA) that included 10 psychosexual/relational milestones in terms of ideal timing revealed a significant main effect, $F(9,441)=338.43, p<.001$. In order of increasing ideal age, these were first kiss, first partner/boyfriend, losing virginity, first time in love, going on holiday with partner, living with partner, becoming engaged, buying a house with partner, getting married, and having first child. The key reproductive events were becoming sexually active (losing virginity, $\mathrm{M}=$ $17.02 \pm .18$ ), making a long term commitment to a partner (getting married, $\mathrm{M}=25.96 \pm$ $.32)$, and having their first child $(\mathrm{M}=27.02 \pm .32)$. These data are shown in Fig. 1 . 


\section{Study 2}

Study 2 sought to extend the above findings to include women who already had children. A 3 (Ideal/Actual: Women with no children ideal, Women with children ideal, Women with children actual) x 5 (Life Event: Losing virginity, Falling in love, Living with partner, Marry, Have first child) ANOVA revealed a significant main effect of life event, $F(4$, $576)=574.11, p<.001$. These data are shown in Fig. 2 and indicated that ideal life plans were very similar between groups and closely adhered to by the women with children in this study, who reported being on average $27.93( \pm .79)$ years old when they had their first child

\section{Study 3}

Women reported having an average of $2.49( \pm .08)$ children, with the first of these being born when they were on average $28.15( \pm .39)$ years old.

\section{Study 4}

ANOVA revealed a significant difference in the age of poor $(\mathrm{M}=23.50+.20)$ and middle class $(\mathrm{M}=24.88 \pm .22)$ women at the birth of their first child, $F(1,861)=21.25, p<$ .001. ANOVA further showed there to be significant differences between the number of children recorded as living with poor $(\mathrm{M}=3.62 \pm .08)$ and middle class $(\mathrm{M}=2.43 \pm .09)$ women at the time of the census, $F(1,861)=92.09, p<.001$. With regard to distributions of women's age at birth of first child, $13.6 \%$ of poor women and $8.9 \%$ of middle class women were in their teens, $76.8 \%$ of poor women and $74.9 \%$ of middle class women were in their $20 \mathrm{~s}$, and $7.5 \%$ of poor women and $12.7 \%$ of middle class women were over the age of 30 . These data together demonstrate that by far the greatest number of first children were born to mothers aged between 20 and 29. These data are presented in more detail in Fig. 3.

\section{DISCUSSION}

Current studies were conducted in order to investigate the hypothesis that physiological and morphological factors combine to produce an optimum age range for 
women to reproduce. Study 1 asked questions about ages at which women thought that particular life events related to reproduction should ideally occur. Data revealed there to be a clear organization in the order of these, with women reporting their ideal age to have their first child to be around 27 years old.

Study 2 sought to replicate these findings and also to determine if this plan translated into actual events. Responses of women without children were found to be similar to those in Study 1 . Women with at least one child indicated that the age at which they had their first child was virtually identical to the reported ideal. Women in Study 1 and in Study 2 further reported their ideal ages for losing their virginities to be in their mid-teens, meaning that they were planning to be (and indeed were) sexually active for around 10 years before first giving birth. These findings demonstrate that the start of sexual activity is not directly related to the desire to have children at that time. Study 3 provided further confirmation that women in these samples were not giving birth until they were in the mid-late 20s. It thus follows that women must be taking active steps to control their own reproduction, which in turn raises the question as to whether this is a purely modern artefact.

Study 4 examined the historical record to determine whether women living in the Victorian era displayed the same patterns of reproduction as modern women. The effects of different income levels were also examined. Findings from this study indicated that the peak of female reproduction was while they were in their early to mid-20s. Further, there was also a marked effect of income level as women living on "poor" streets tended to have their first child 1-1.5 years earlier than those living on "middle class" streets. They also typically had more children. While these findings are clear, it must be recognized that they were estimates. The method for calculating mother's age at birth of first child involved subtracting the eldest child's age from her own age. This is, of course, sensitive to circumstances where children were not in the household at the time of the census. However, information about the reasons 
for a child's absence was not available. In an effort to control for this, "well to do" women were selected for comparison rather than those in "wealthy" households, since their children were less likely to be away at boarding school.

A further source of possible error was the effect of infant mortality. In families where the first-borns had died, the woman's age at birth of first child would have been based on the birth of her second or subsequent child and so estimated to be higher than it actually was.

Differences in access to medical care meant that the effects of this would have been greater in the "poor" group. In this context, it is important to note that the consequence would have been to reduce the differences between "poor" and "middle class" groups rather than to exacerbate them. Similarly, data were sensitive to children having reached maturity and having left the family home. However, this appears not to have been a major factor in the current sample as age of eldest child in the household increased in parallel with mother's age rather than levelling off as would otherwise be expected. These data, therefore, show that women's patterns of reproduction were remarkably consistent across time and apparent even in an age where modern contraception was not freely available.

Women delaying their reproduction for at least a decade beyond the onset of their fertility is an evolutionary paradox that requires explanation. In this context, the conflicting demands of bipedal locomotion and childbirth have introduced an obstetric dilemma into our species (Rosenberg \& Trevathan, 2002; Stewart, 1984; Wittman \& Wall, 2007) with the result that women's hips are only just wide enough to allow the passage of a child. This effect is exacerbated by increased encephalization which has led to human infants being born at an earlier stage of development than is typical of other primates (DeSilva \& Lesnik, 2006, 2008). There are many other serious complications associated with this obstetric difficulty, including fistula damage and high maternal/neonatal mortality rates (Leung \& Chung, 2009). Hip morphology is, therefore, a major limiting factor on women's ability to reproduce. Full 
adult form is not reached until the mid-20s (e.g., Sheiner et al., 2005) and so this alone would be sufficient to explain why females seek to delay their reproduction for an extended period beyond menarche.

Women are not, however, always in control of their own reproductive destinies and factors such as economic conditions and cultural norms can exert a powerful influence. For example, religious laws and traditional practices such as arranged marriages encourage reproduction at an early age, while secular laws seek to restrict the age at which sexual activity can begin. There is, however, a wide variation of ages of consent indicating that there is no universally agreed consensus (Graupner, 2000; Posner \& Silbaugh, 1996). In the UK, the current age of consent is 16 while in 1875 this was 13 (Waites, 2004). Similarly, in the U.S. state of Wisconsin, it is 18 while in the 1880s it was 10 (Boos, 2002). Environmental conditions exert a similar influence whereby economic deprivation can induce what might be called a "fast cycle" where affected individuals tend to reproduce early (Elias et al., 2007; Nettle, 2012) and inter-generational gaps are short (Matthews \& Sun, 2006).

Therefore, current data clearly demonstrate the existence of a preferred female reproductive strategy. It is proposed that this is a response to those physiological and morphological factors that place restrictions on the timing of women's reproduction. The consequence, is that the optimum time for childbirth is some 10 years after the onset of menarche. Reproduction significantly in advance of this optimum increases the risks of birth related difficulties which may have deleterious consequences for both mother and infant. Reproduction much beyond this represents wasted opportunity. Hence, the declared preference in the modern era for mother's age at birth of first child to be around 26-27 and this being reflected in actual reproductive patterns. It cannot be stated with certainty that women in Victorian times also aspired to delay reproduction until their mid-20s but data 
relating to mother's age at birth of first child (particularly in the middle class group) are nonetheless strongly indicative of this.

In conclusion, the boundaries of women's fertility are defined by menarche and menopause. Slow hip growth represents a further restriction whereby the full adult form is not typically reached until women are in their mid-20s. Therefore, while there might by a number of other cultural or social factors that may account for this, restrictions imposed by hip morphology and maturation are alone sufficient explanation for women's preference for a lengthy delay between onset of menarche and reproduction. Further studies are required to determine if this is applies to a broader population. 


\section{REFERENCES}

Asada, H., Sueoka, K., Hashiba, T., Kuroshima, M., Kobayashi, N., \& Yoshimura, Y. (2000). The effects of age and abnormal sperm count on the nondisjunction of spermatozoa. Journal of Assisted Reproduction and Genetics, 17, 51-59.

Backman, G. (1948). Die beschleunigte Entwicklung der Jugend: Verfrühte Menarche verspätete Menopause, verlängerte Lebensdauer. Acta Anatomica, 4, 421-480.

Beise, J. (2005). The helping grandmother and the helpful grandmother: The role of maternal and paternal grandmothers in child mortality in the $17^{\text {th }}$ and $18^{\text {th }}$ century population of French settlers in Quebec, Canada. In E. Voland, A. Chasiotis, \& W. Schiefenhoevel (Eds.), Grandmotherhood: The evolutionary significance of the second half of the female life (pp. 215-238). New Brunswick, NJ: Rutgers University Press.

Benzies, K. M., Tough, S., Tofflemire, K., Frick, C., Faber, A., \& Newburn-Cook, C. (2006). Factors influencing women's decisions about the timing of motherhood. Journal of Obstetric, Gynecologic and Neonatal Nursing, 35, 625-633.

Boos, E. J. (2002). Strange brew: The Wisconsin brewing industry's opposition to prohibition, women's suffrage, and the age of consent laws. Southern California Review of Law \& Women's Studies, 12, 3.

Booth, C. (1902). Life and labour of the people in London ( $3^{\text {rd }}$ ed.). London: Macmillan.

Bosch, M., Rajmil, O., Martinez-Pasarell, O., Egozcue, J., \& Templado, C. (2001). Linear increase of diploidy in human sperm with age: A four-colour FISH study. European Journal of Human Genetics, 9, 533-538.

Brown, P. E. (1996). The age at menarche. British Journal of Preventive \& Social Medicine, 20, 9-14.

Buss, D. M., \& Schmitt, D. P. (1993). Sexual strategies theory: An evolutionary perspective on human mating. Psychological Review, 100, 204-232. 
Callaghan, W. M., \& Berg, C. J. (2003). Pregnancy-related mortality among women aged 35 years and older, United States, 1991-1997. Obstetrics \& Gynecology, 102, 1015-1021.

Chahande, M. S., Jadho, A. R., Wadhva, S. K., \& Udhade, S. (2002). Study of some epidemiological factors in teenage pregnancy-hospital based case comparison study. Indian Journal of Community Medicine, 27, 106-109.

Chen, X. K., Wen, S. W., Fleming, N., Yang, Q., \& Walker, M. C. (2008). Increased risks of neonatal and postneonatal mortality associated with teenage pregnancy had different explanations. Journal of Clinical Epidemiology, 61, 688-694.

Creatsas, G., \& Elsheikh, A. (2002). Adolescent pregnancy and its consequences. European Journal of Contraception and Reproductive Health Care, 7, 167-172.

Cunnington, A. J. (2001). What's so bad about teenage pregnancy? Journal of Family Planning and Reproductive Health Care, 27, 36-41.

DeSilva, J. M., \& Lesnik, J. J. (2006). Chimpanzee neonatal brain size: Implications for brain growth in Homo erectus, Journal of Human Evolution, 51, 207-212.

DeSilva, J. M., \& Lesnik, J. J. (2008). Brain size at birth throughout human evolution: A new method for estimating neonatal brain size in hominins. Journal of Human Evolution, 55, 1064-1074.

Elias, S. G., van Noord, P. A. H., Peeters, P. H. M., den Tonkelaar, I., Kaaks, R., \& Grobbee, D. E. (2007). Menstruation during and after caloric restriction: The 1944-1945 Dutch famine. Fertility and Sterility, 88, 111-1107.

Geary, D. (2000). Evolution and proximate expression of human paternal investment. Psychological Bulletin, 126, 55-77.

Gettler, L. T. (2010). Direct male care and hominin evolution: Why male-child interaction is more than a nice social idea. American Anthropology, 112, 7-21. 
Graupner, H. (2000). Sexual consent: The criminal law in Europe and overseas. Archives of Sexual Behavior, 29, 415-461

Guegan, J. F., Teriokhin, A. T., \& Thomas, F. (2000). Human fertility variation, size-related obstetrical performance and the evolution of sexual stature dimorphism. Proceedings of the Royal Society B: Biological Sciences, 22, 2529-2535.

Hassold, T. (1986). Chromosome abnormalities in human reproduction wastage. Trends in Genetics, 2, 105-110.

Hendrie, C. A., \& Brewer, G. (2010). Kissing as an evolutionary adaptation to protect against human cytomegalovirus-like teratogenesis. Medical Hypotheses, 74, 222-224.

Jolly, M. C., Sebire, N., Harris, J., Robinson, S., \& Regan, L. (2000). Obstetric risks of pregnancy in women less than 18 years old. Obstetrics \& Gynecology, 96, 962-966.

Kenrick, D. T., Sadalla, E. K., Groth, G., \& Trost, M. R. (1990). Evolution, traits, and the stages of human courtship: Qualifying the parental investment model. Journal of Personality, 58, 97-117.

LaVelle, M. (1994). Are there long-term health consequences of secular trend in early menarche? Collegium Antropologicum, 18, 53-61.

Lawlor, D. A., Smith, G. D., \& Ebrahim, S. (2004). Birth weight is inversely associated with coronary heart disease in post-menopausal women: Findings from the British women's heart and health study. Journal of Epidemiology \& Community Health, 58, $120-125$.

Leung, T. Y., \& Chung, T. K. H. (2009). Severe chronic morbidity following childbirth. Best Practice \& Research in Clinical Obstetrics, 23, 401-123.

Martin. R. (2007). The evolution of human reproduction: A primatological perspective. American Journal of Physical Anthropology, 45, S59-84. 
Matthews, S. H., \& Sun, R. (2006). Incidence of four-generation family linkages: Is timing of fertility or mortality a better explanation? Journals of Gerontology B-Psychology, 61B, S99-S106.

McClure, E. M., Goldenberg, R. L., \& Bann, C. M. (2007). Maternal mortality, stillbirth and measures of obstetric care in developing and developed countries. International Journal of Gynecology \& Obstetrics, 96, 139-146.

Nettle, D. (2012). Flexibility in reproductive timing in human females: Integrating ultimate and proximate explanations. Philosophical Transactions of the Royal Society B: Biological Sciences, 366, 357-365.

Phipps, M. G., Blume, J. D., \& DeMonner, S. M. (2002). Young maternal age associated with increased risk of postneonatal death. Obstetrics \& Gynecology, 100, 481-486.

Posner, R. A., \& Silbaugh, K. B. (1996). A guide to America's sex laws. University of Chicago Press: Chicago, IL.

Richards, M., Hardy, R., Kuh, D., \& Wadsworth, M. E. J. (2001). Birth weight and cognitive function in the British 1946 birth cohort: Longitudinal population based study. British Medical Journal, 322, 199-203.

Rosenberg, K., \& Trevathan, W. (2002). Birth, obstetrics and human evolution. International Journal of Obstetrics \& Gynecology, 109, 1199-1206.

Salihu, H. M., Shumpert, M. N., Slay, M., Kirby, R. S., \& Alexander, G. R. (2003). Childbearing beyond maternal age 50 and fetal outcomes in the United States. Obstetrics \& Gynecology, 103, 1006-1014.

Schwarz, E. B., Smith, R., Steinauer, J., Reeves, M. F., \& Caughey, A. B. (2008). Measuring the effects of unintended pregnancy on women's quality of life. Contraception, 78, 204-210. 
Sheiner, E., Levy, A., Katz, M., \& Mazor, M. (2005). Short stature-an independent risk factor for Cesarean delivery. European Journal of Obstetrics \& Gynecology and Reproductive Biology, 120, 175-178.

Stewart, D. (1984). The pelvis as passageway II. The modern human pelvis. British Journal of Obstetrics \& Gynaecology, 91, 618-623.

Volarcik, K., Sheean, L., Goldfarb, J., Woods, L., Abdul-Karim, F. W., \& Hunt, P. (1998). The meiotic competence of in-vitro human oocytes is influenced by donor age: Evidence that folliculogenesis is comprised in the reproductively aged ovary. Human Reproduction, 13, 154-160.

Waites, M. (2004). The age of consent and sexual consent. In: M. Cowling \& P. Reynolds (Eds.), Making sense of sexual consent (pp. 73-92). Aldershot, UK: Ashgate.

Wittman, A. B., \& Wall, L. L. (2007). The evolutionary origins of obstructed labour: Bipedalism, encephalization, and the human obstetric dilemma. Obstetrical \& Gynecological Survey, 62, 739-748. 


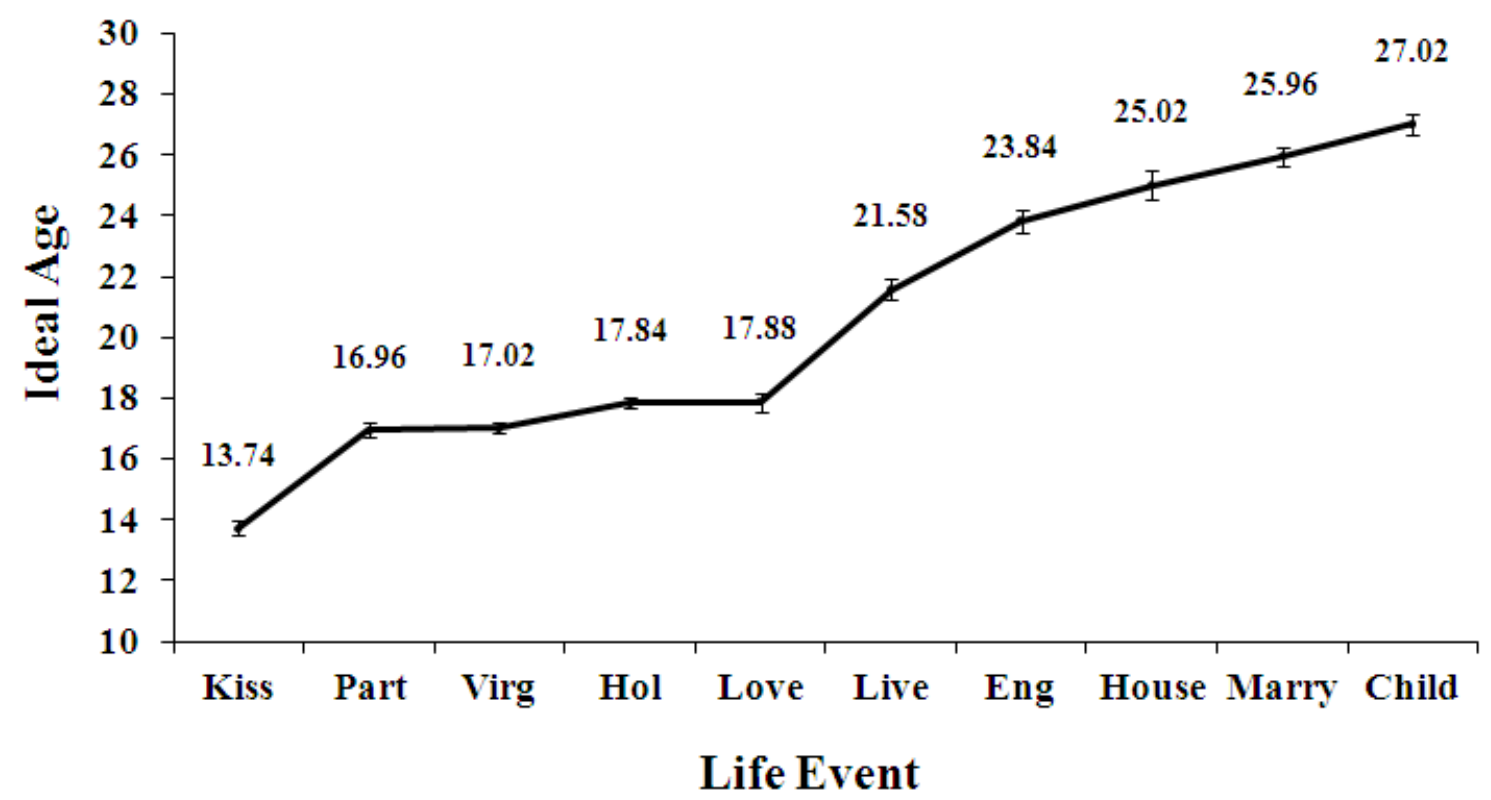

Figure 1. The female life plan. Data are expressed as M age $( \pm$ SEM $)$ that females indicated that particular life events should ideally occur. These life events were first kiss, first partner/boyfriend (Part), losing their virginity (Virg), going on holiday with their partner (Hol), first time in love, living with their partner (Live), becoming engaged (Eng), buying first home together (House), getting married and having their first child. Means are given above each data point. 


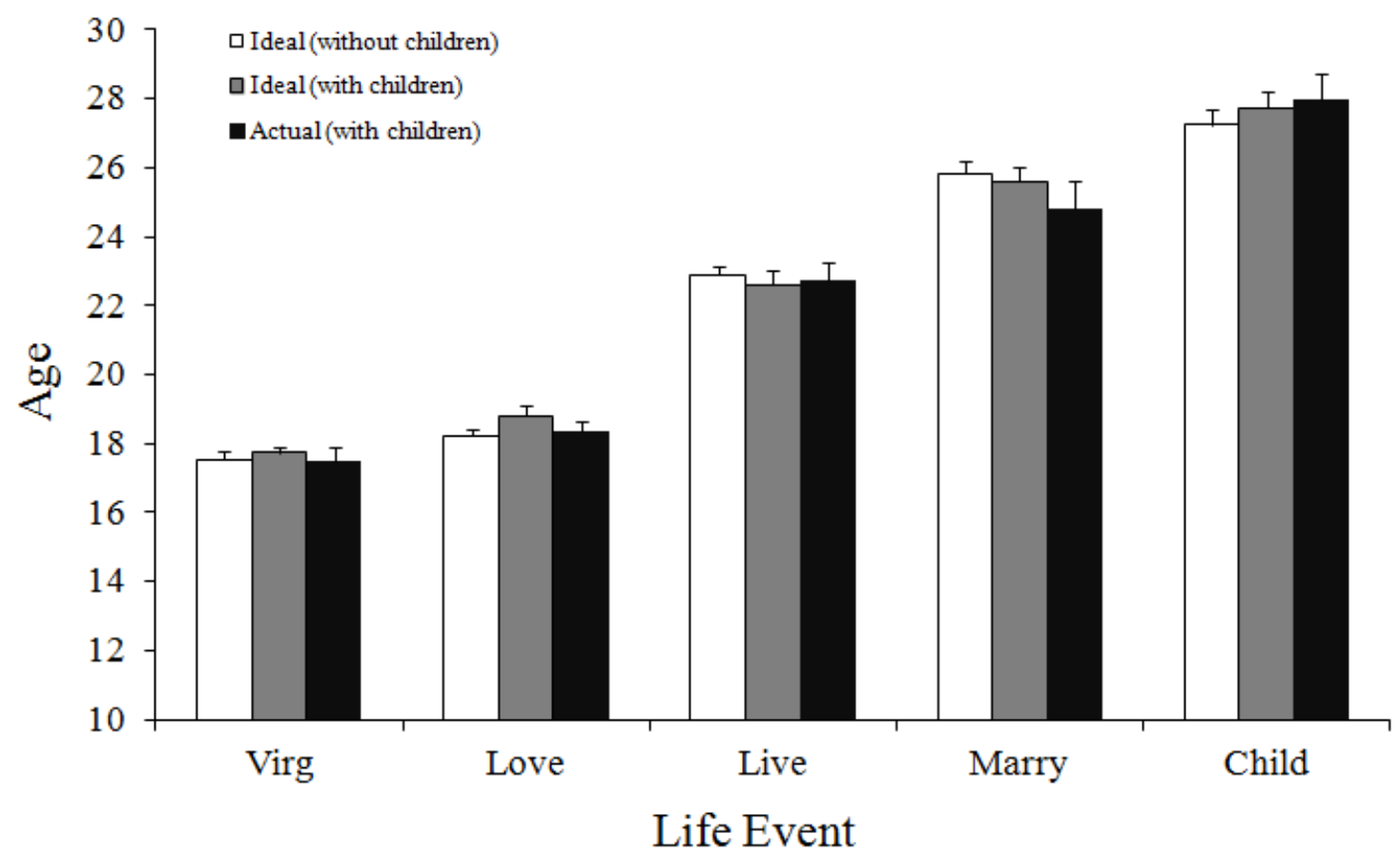

Figure 2. Ideal and reported life events by women with no children and those with at least one. Data are expressed as M ( + SEM) ideal or reported age in years for each life event to occur. These life events were losing their virginity (Virg), first time in love, living with their partner (Live), getting married and having their first child. 


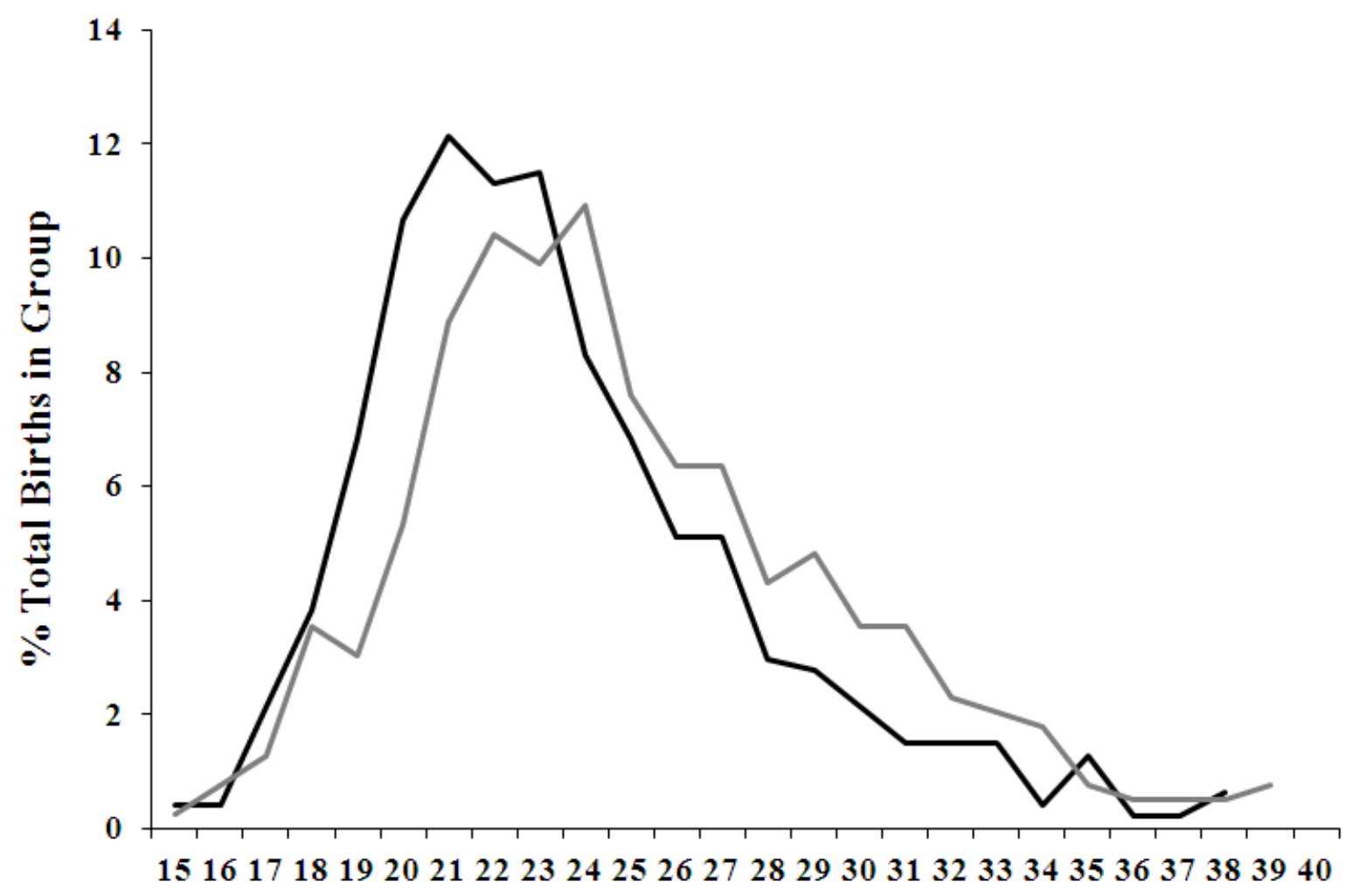

Age at Birth of First Child

Figure 3. Distribution of women's ages (years) at the birth of their first child as measured by information given in the 1901 UK census. Data are expressed as percentage of total births at each age in samples of women identified as living in poor (dark line) or middle class (light line) streets on Booth's poverty map of London (Booth, 1902). 